\title{
EXPANSÃO URBANA NAS GRANDES METRÓPOLES o significado das migrações intrametropolitanas e da mobilidade pendular na reprodução da pobreza
}

FAusto Brito

Joseane de SouzA

\begin{abstract}
Resumo: O objetivo primeiro deste artigo é analisar a simultaneidade do processo de urbanização e de concentração da população urbana nos grandes aglomerados metropolitanos na segunda metade do século passado no Brasil. Como decorrência, também será estudado o processo de redistribuição da população dentro dos aglomerados na perspectiva da metropolização da pobreza, tendo como referência a Região Metropolitana de Belo Horizonte.

Palavras-chave: Urbanização. Metrópoles. Migrações.

Abstract: The main purpose of this paper is to analyze the simultaneity of the urbanization and urban population concentration process in big metropolitan cities occurred in last century's second half in Brazil. As a result, will be analyzed the population redistribution process inside the metropolitan areas using the idea of poverty redistribution. In this paper Belo Horizonte's Metropolitan Area will be used as reference.

Key words: Urbanization. Metropolitan areas. Migrations.
\end{abstract}

$\Lambda$ grande expansão urbana no Brasil é relativamente recente. Seu início articula-se com um conjunto de mudanças estruturais na economia e na sociedade brasileira a partir da década de 30 do século 20, mas somente em 1970 os dados censitários revelaram uma população urbana superior à rural.

Isso não quer dizer que as cidades já não fizessem parte da paisagem social do país desde os períodos da colônia e do Império, apesar de suas restritas dimensões demográficas. Na República Velha (1889/1930), com a grande expansão da economia cafeeira, e com o primeiro e expressivo surto de industrialização, ampliaram-se as relações mercantis entre as diferentes regiões brasileiras - até então, meros arquipélagos regionais - e começaram a se intensificar as migrações, principalmente as internacionais. Estas, fortemente financiadas pelo Estado, impunham limites à expansão dos deslocamentos populacionais inter- nos - que começavam a dirigir-se, prioritariamente, para os Estados onde a economia mais se expandia, ou seja, São Paulo e Rio de Janeiro.

Esses arquipélagos regionais, fundamentalmente articulados em torno das atividades agrícolas, mantinham um sistema de cidades polarizadas, geralmente, pelas capitais dos Estados. A população urbana distribuía-se pelos diferentes sistemas regionais de cidades, fundamentalmente litorâneos e fortemente concentrados na região Sudeste. Somente então, a partir da República Velha, é que esses arquipélagos regionais começaram a articular-se, nacionalmente, dentro de um processo de integração mercantil comandado pelo complexo da economia cafeeira capitalista.

A partir dos anos 30 e 40, a urbanização incorporou-se às profundas transformações estruturais por que passavam a sociedade e a economia brasileira. Ela assume, de fato, uma dimensão estrutural: não é só o território que 
acelera o seu processo de urbanização, mas é a própria sociedade brasileira que se transforma cada vez mais em urbana. Essa grande transformação urbana acompanhará o acelerado processo de industrialização da economia brasileira, que tem como marco inicial mais importante a segunda metade da década de 50, quando vai-se tornando cada vez mais intensa com a expansão dos sistemas de transportes e dos meios de comunicação de massas. Essa grande transformação deve ser entendida como a construção irreversível da hegemonia do urbano, não só como o locus privilegiado das atividades econômicas mais relevantes e da população, mas também como difusora dos novos padrões de relações sociais - inclusive as de produção e estilos de vida.

O Brasil arcaico, fortemente vinculado a uma estrutura agrária em profunda transformação, desarticulava-se até mesmo nas regiões de expansão da fronteira agrícola, onde, rapidamente, a economia camponesa cedia lugar ao grande capital. Essa grande mudança da sociedade brasileira, na segunda metade do século 20, incorporava como um dos seus principais vetores de transformação o chamado "grande ciclo de expansão das migrações internas". As migrações internas faziam o elo maior entre as mudanças estruturais por que passavam a sociedade e a economia brasileira e a aceleração do processo de urbanização (BRITO; HORTA, 2002).

Essa tendência a um crescente aumento no grau de urbanização não constituiu uma novidade histórica. Os países capitalistas de primeira geração - como a Inglaterra e os de segunda geração - como os do continente europeu, os Estados Unidos e o Japão - apresentaram, todos, a mesma tendência, ou seja, uma maciça transferência da população do campo para as cidades, chegando a graus de urbanização que variam entre $85,0 \%$ a 95,0\%.

A grande novidade, no caso brasileiro, semelhante a alguns outros países em desenvolvimento, foi a velocidade do processo de urbanização, muito superior à dos países capitalistas mais avançados. Somente na segunda metade do século 20, a população urbana passou de 19 milhões para 138 milhões, multiplicando-se 7,3 vezes, com uma taxa média anual de crescimento de 4,1\%. Ou seja, a cada ano, em média, nessa última metade de século, 2.378.291 habitantes eram acrescidos à população urbana.

No auge da expansão urbana, as altas taxas de fecundidade ainda tiveram grande importância para esse excepcional crescimento demográfico, pois somente a partir da segunda metade da década de 60, quando ela se acelera e se generaliza, há o declínio dos níveis de fecundidade.
Contudo, a maior parte do crescimento demográfico urbano deve ser explicada pelo intenso fluxo migratório ruralurbano, dentro do contexto do grande ciclo de expansão das migrações internas. Somente entre 1960 e o final dos anos 80 , o auge do ciclo, estima-se que saíram do campo em direção às cidades quase 43 milhões de pessoas - total que inclui o chamado "efeito indireto da migração", ou seja, os filhos tidos pelos migrantes rurais nas cidades. Tratase de um deslocamento populacional gigantesco, num breve espaço de tempo, o que bem qualifica a dimensão das grandes transformações pelas quais passava a sociedade brasileira (CARVALHO; GARCIA, 2003).

Como foi mencionado, a migração interna em geral - e não só a rural-urbana - constituiu um dos elos mais importantes entre as profundas mudanças estruturais e a grande transformação urbana. O intenso crescimento da economia urbano-industrial - que se deu depois do Plano de Metas e se estendeu até o final dos anos 70 - foi, do ponto de vista espacial e social, extremamente desequilibrado. Muito concentrado no Estado do Rio de Janeiro e, mais ainda, em São Paulo, o desenvolvimento da economia ampliou os desequilíbrios regionais, inclusive entre a cidade e o campo, uma vez que este não conseguia gerar o número de empregos que atendesse ao crescimento da sua força de trabalho. As migrações internas redistribuíam a população do campo para as cidades, entre os Estados e as diferentes regiões do Brasil, inclusive onde se expandia a fronteira agrícola. Mas elas se dirigiam, principalmente, para as regiões metropolitanas, muito especialmente as do $\mathrm{Su}$ deste - e, principalmente, a de São Paulo. Apesar do grande crescimento da economia e da oferta de empregos até o final da década de 70, as migrações internas, frutos dos desequilíbrios econômicos e sociais nas regiões de origem, acabavam por reproduzi-los nas regiões de destino.

Essa maciça redistribuição da população favorável às cidades e, em destaque, às cidades metropolitanas, contribuiu para definir um novo perfil para a sociedade brasileira. Desde a sua criação, no início dos anos 70, até os dias atuais, as regiões metropolitanas sofreram inúmeras transformações, com a incorporação de novos municípios. Como essa decisão é da competência das Assembléias Legislativas, freqüentemente a delimitação de uma região metropolitana obedece muito mais a critérios políticos do que aos sociais, econômicos e demográficos.

Com o propósito de analisar mais fidedignamente a realidade dos aglomerados metropolitanos, neste artigo será utilizado o estudo desenvolvido pelo Instituto de Pesquisa Econômica Aplicada - Ipea, e do conjunto formado pelo 
Núcleo de Economia Social, Urbana e Regional/Instituto de Economia da Universidade de Campinas - Nesur/IEUnicamp e o Instituto Brasileiro de Geografia e Estatística - IBGE, no qual foram identificados os grupos de cidades que realmente constituíam o verdadeiro aglomerado metropolitano (IPEA/IBGE/NESUR, 1999). Para definir o espaço urbano que realmente pudesse ser considerado um aglomerado metropolitano, foram empregados indicadores demográficos e econômicos, assim como dos fluxos de bens e serviços. Nesse artigo, optou-se por selecionar, dentre os grupos de cidades estabelecidos, aqueles que foram considerados aglomerações metropolitanas globais - São Paulo e Rio de Janeiro - e as aglomerações metropolitanas nacionais - Belém, Fortaleza, Recife, Salvador, Belo Horizonte, Campinas, Curitiba, Porto Alegre, Goiânia e Brasília (Tabela 1).

A tendência à concentração populacional nos grandes aglomerados metropolitanos já era bastante nítida nos anos 70 e 80 , como resultado do fantástico fluxo migratório verificado no período. Em 1970, contabilizava-se uma população de cerca de 93 milhões de habitantes para o país e aproximadamente um terço desse total tinha como residência municípios pertencentes às aglomerações metropolitanas. Considerando-se somente a população urbana, essa proporção chega a quase 50\%. Levando em conta que foi somente na década de 60 que a população urbana superou a rural, pode-se afirmar que a transformação urbana no Brasil foi tão acelerada que fez coincidir, no tempo, a urbanização e a metropolização.

Como conseqüência dessa característica estrutural marcante da sociedade brasileira, no final do século passado um terço de sua população residia nos aglomerados metropolitanos selecionados. Quanto à população urbana - cuja metade já era metropolitana em 1970 - há um relativo declínio. No final do século, apesar de ter mais do que dobrado nas três últimas décadas, passando de 25 milhões para 56 milhões, a participação relativa da população metropolitana no total da população urbana passa para 41,0\% (Tabela 1). Essa redução foi resultante do redirecionamento de parte das migrações internas, depois de 1980, para as cidades médias não metropolitanas (BRITO; HORTA, 2002).

TABELA 1

População, segundo Aglomerados Metropolitanos Brasil - 1970-2000

\begin{tabular}{|c|c|c|c|c|}
\hline Aglomerados Metropolitanos & 1970 & 1980 & 1991 & 2000 \\
\hline Belém & 669.768 & 1.021 .486 & 1.401 .305 & 1.794 .981 \\
\hline Fortaleza & 1.070 .114 & 1.627 .042 & 2.339 .538 & 2.901 .040 \\
\hline Recife & 1.755 .083 & 2.347 .005 & 2.874 .555 & 3.272 .322 \\
\hline Salvador & 1.135 .818 & 1.752 .839 & 2.474 .385 & 2.988 .610 \\
\hline Belo Horizonte & 1.619 .792 & 2.570 .281 & 3.385 .386 & 4.161 .028 \\
\hline Rio de Janeiro & 6.879 .183 & 8.758 .420 & 9.796 .649 & 10.847 .106 \\
\hline São Paulo & 8.113 .873 & 12.552 .203 & 15.395 .780 & 17.768 .135 \\
\hline Campinas & 644.490 & 1.221 .104 & 1.778 .821 & 2.215 .027 \\
\hline Curitiba & 809.305 & 1.427 .782 & 1.984 .349 & 2.634 .410 \\
\hline Porto Alegre & 1.590 .798 & 2.307 .586 & 3.029 .073 & 3.495 .119 \\
\hline Goiânia & 424.588 & 807.626 & 1.204 .565 & 1.606 .955 \\
\hline Brasília & 625.916 & 1.357 .171 & 1.980 .432 & 2.746 .747 \\
\hline Total dos Aglomerados & 25.338 .728 & 37.750 .545 & 47.644 .838 & 56.431 .480 \\
\hline População do Brasil & 93.134 .846 & 119.002 .706 & 146.825 .475 & 169.544 .443 \\
\hline Aglomerado/Brasil (\%) & 27,21 & 31,72 & 32,45 & 33,28 \\
\hline População Urbana & 52.097 .271 & 80.436 .409 & 110.990 .990 & 137.697 .439 \\
\hline Aglomerado Urbano (\%) & 48,64 & 46,93 & 42,93 & 40,98 \\
\hline
\end{tabular}

Fonte: IBGE. Censos Demográficos 1970 a 2000. 
O crescimento demográfico das aglomerações metropolitanas tem sido declinante. Para melhor compreendê-lo, será feita a distinção entre o núcleo, que é a capital, e os demais municípios, que formam a periferia metropolitana. As capitais têm tido uma redução bastante acentuada em seu ritmo de crescimento. As maiores cidades brasileiras, como São Paulo, Rio de Janeiro e Belo Horizonte, na última década do século 20, tiveram um crescimento anual extremamente baixo. Deve ser sublinhado que, em função do tamanho da população dessas cidades, seu pequeno crescimento representou $40,0 \%$ do total da população dos aglomerados metropolitanos. Nessa direção da redução da velocidade do seu crescimento demográfico, caminham todos os núcleos dos aglomerados metropolitanos. Isso ocorre, em parte, pelo acentuado declínio das taxas de fecundidade, mas sobretudo pela redução de seus saldos migratórios (Tabela 2).

As periferias tiveram nos anos 70 e 80 um crescimento espetacular que ainda se mantém bastante alto, apesar de declinante, pois elas também sofrem o impacto da redução da fecundidade e das migrações. Mesmo assim, nas duas últimas décadas, a velocidade de seu crescimento permaneceu em torno de 3,0\% ao ano. A crise econômica vivenciada pelo país provocou grande redução da oferta de empregos e somou-se à profunda crise social urbana, que tem afetado, em particular, os grandes aglomerados metropolitanos. Assim, juntas, funcionaram como "freio" a uma possível tendência de hipermetropolização. Entretanto, um fato não pode deixar de ser sublinhado: na década de 90, houve uma substancial desaceleração na queda das taxas de crescimento do conjunto de aglomerados metropolitanos - o que possibilitou até mesmo um aumento do incremento médio anual de sua população: de 899.481 habitantes, na década anterior, para 985.418.

De qualquer modo, os dados reafirmam a grande especificidade do processo de urbanização no Brasil - a simultaneidade da urbanização com a metropolização acrescentando ainda uma nova característica: dentro dos aglomerados metropolitanos, há uma notável tendência a um maior crescimento dos municípios periféricos em relação às capitais. Isso pode ser melhor observado quando se utiliza como indicador a contribuição relativa do núcleo, ou das capitais, para o crescimento absoluto dos aglomerados metropolitanos.

Quando se analisa a contribuição do núcleo para o crescimento do aglomerado, nota-se que nos anos 80 ela já era inferior a 50,0\% - e isto significa que as periferias começavam a ter o comando do crescimento demográfico metropolitano (Tabela 3). Na década de 90, o peso dos núcleos metropolitanos continua a se reduzir, e os demais municípios passam a responder por $62,0 \%$ do incremento total da população metropolitana - proporção maior do que a do

TABELA 2

Taxas de Crescimento Anual do Núcleo e da Periferia dos Aglomerados Metropolitanos Brasil - 1970-2000

\begin{tabular}{|c|c|c|c|c|c|c|}
\hline \multirow{2}{*}{ Aglomerados } & \multicolumn{3}{|c|}{ Núcleo } & \multicolumn{3}{|c|}{ Periferia } \\
\hline & $1970 / 80$ & $1980 / 91$ & $1991 / 2000$ & $1970 / 80$ & $1980 / 91$ & $1991 / 2000$ \\
\hline Total dos Aglomerados & 3,49 & 1,50 & 1,21 & 5,32 & 3,28 & 2,99 \\
\hline Belém & 3,95 & 2,65 & 0,31 & 9,26 & 5,36 & 14,29 \\
\hline Fortaleza & 4,30 & 2,78 & 2,15 & 4,18 & 5,42 & 3,31 \\
\hline Recife & 1,27 & 0,69 & 1,03 & 5,11 & 2,96 & 1,82 \\
\hline Salvador & 4,08 & 2,98 & 1,84 & 6,91 & 4,31 & 3,62 \\
\hline Belo Horizonte & 3,73 & 1,15 & 1,11 & 7,45 & 5,11 & 3,97 \\
\hline Rio de Janeiro & 1,82 & 0,67 & 0,74 & 3,39 & 1,49 & 1,66 \\
\hline São Paulo & 3,67 & 1,16 & 0,85 & 6,37 & 3,22 & 2,81 \\
\hline Campinas & 5,86 & 2,24 & 1,50 & 7,56 & 4,79 & 3,33 \\
\hline Curitiba & 5,34 & 2,29 & 2,13 & 7,24 & 4,72 & 5,15 \\
\hline Porto Alegre & 2,43 & 1,06 & 0,83 & 5,30 & 3,71 & 2,16 \\
\hline Goiânia & 6,54 & 2,31 & 1,90 & 7,48 & 10,94 & 7,01 \\
\hline Brasília & 8,15 & 2,84 & 2,77 & 7,38 & 7,00 & 7,18 \\
\hline
\end{tabular}

Fonte: IBGE. Censos Demográficos 1970 a 2000. 
TABELA 3

Participação do Núcleo no Incremento Populacional Médio Anual do Aglomerado

Brasil - 1970-2000

\begin{tabular}{|c|c|c|c|}
\hline & & & Em porcentagem \\
\hline Aglomerados Metropolitanos & $1970 / 80$ & $1980 / 91$ & $1991 / 2000$ \\
\hline Total dos Aglomerados & 58,50 & 45,10 & 37,93 \\
\hline Belém & 85,27 & 81,99 & 8,93 \\
\hline Fortaleza & 80,73 & 64,71 & 65,82 \\
\hline Recife & 24,19 & 17,88 & 31,10 \\
\hline Salvador & 80,19 & 79,45 & 71,10 \\
\hline Belo Horizonte & 57,43 & 29,36 & 27,01 \\
\hline Rio de Janeiro & 44,63 & 37,57 & 35,20 \\
\hline São Paulo & 57,87 & 40,55 & 32,03 \\
\hline Campinas & 50,07 & 32,82 & 27,58 \\
\hline Curitiba & 67,25 & 52,12 & 41,82 \\
\hline Porto Alegre & 33,47 & 19,12 & 20,71 \\
\hline Goiânia & 87,92 & 51,57 & 41,84 \\
\hline Brasília & 87,44 & 68,06 & 57,69 \\
\hline
\end{tabular}

Fonte: IBGE. Censos Demográficos 1970 a 2000.

núcleo na década de 70. As únicas aglomerações metropolitanas que ainda apresentavam maior contribuição do núcleo, em 2000, eram Fortaleza, Salvador e Brasília. Entretanto, em consonância com as demais, ao longo do período considerado, elas têm diminuído sua importância relativa. Os dados indicam que o processo de metropolização tem sido marcado pela redistribuição da população metropolitana favorável aos municípios periféricos, certamente estimulada pela emigração da capital em direção às demais cidades das aglomerações metropolitanas.

Assim, este artigo vai tomar como referência a Região Metropolitana de Belo Horizonte - RMBH para estudar o verdadeiro significado dos processos intrametropolitanos - principalmente os de migração e mobilidade.

Nos aglomerados metropolitanos, tem havido uma tendência ao deslocamento das atividades econômicas, principalmente as industriais, das capitais para os outros municípios, como decorrência das pressões do capital imobiliário pelo uso dos espaços urbanos mais nobres e pela ação do Estado - o que promove a regionalização econômica e facilita as economias de aglomeração. Essa realocação espacial das atividades econômicas e a ação concomitante do capital imobiliário proporcionaram uma redistribuição espacial da população através de uma intensa migração - prioritariamente, entre a capital dos aglomerados urbanos e os municípios vizinhos. Finalmente, as mudanças econômicas e as conseqüentes migrações têm implicado num grande movimento pendular da população: entre os residentes nos municípios vizinhos e a capital; e entre essa última e os primeiros, ainda que numa proporção menor (BRITO; SOUZA, 2005).

A RMBH está inserida na dinâmica demográfica e econômica dos grandes aglomerados metropolitanos. Sendo uma cidade relativamente recente, com pouco mais de cem anos, Belo Horizonte foi criada e planejada com o objetivo explícito de manter regulada a distribuição espacial e social da população. No decorrer de sua breve história, Estado e capital imobiliário promoveram uma permanente redistribuição espacial da população, de acordo com as exigências do padrão de expansão urbana - que tem como uma de suas características básicas a segregação espacial da população mais pobre. Com o tempo, a expansão urbana da capital extrapolou seus limites, invadindo os municípios vizinhos e metropolizando a segregação social dos mais pobres (BRITO; SOUZA, 2005).

Em 2000, a RMBH tinha cerca de 4,4 milhões de habitantes, sendo que $51,5 \%$ deles ainda residiam na capital proporção essa com nítida tendência decrescente (Tabela 4 e Gráfico 1). Como o núcleo do aglomerado metropolitano também obedece às mesmas características das maiores capitais brasileiras, suas taxas de crescimento demográfico têm apresentado considerável desaceleração. Atualmente, seu ritmo é muito inferior à média do conjunto dos outros municípios metropolitanos (Gráfico 2). 
TABELA 4

Evolução da População

Região Metropolitana de Belo Horizonte - 1940-2000

\begin{tabular}{lccc}
\hline Anos & BH & RRMBH (1) & RMBH \\
\hline 1940 & 211.377 & 157.407 & 368.784 \\
1950 & 352.724 & 170.195 & 522.919 \\
1960 & 693.328 & 237.955 & 931.283 \\
1970 & 1.235 .030 & 484.460 & 1.719 .490 \\
1980 & 1.780 .855 & 895.537 & 2.676 .392 \\
1991 & 2.020 .161 & 1.494 .840 & 3.515 .001 \\
2000 & 2.238 .526 & 2.108 .158 & 4.346 .684 \\
\hline
\end{tabular}

Fonte: IBGE. Censos Demográficos 1940 a 2000.

(1) Municípios metropolitanos menos Belo Horizonte.

\section{GRÁFICO}

Evolução da População

Região Metropolitana de Belo Horizonte - 1940-2000

口Belo Horizonte $\quad$ RRMBH (1)

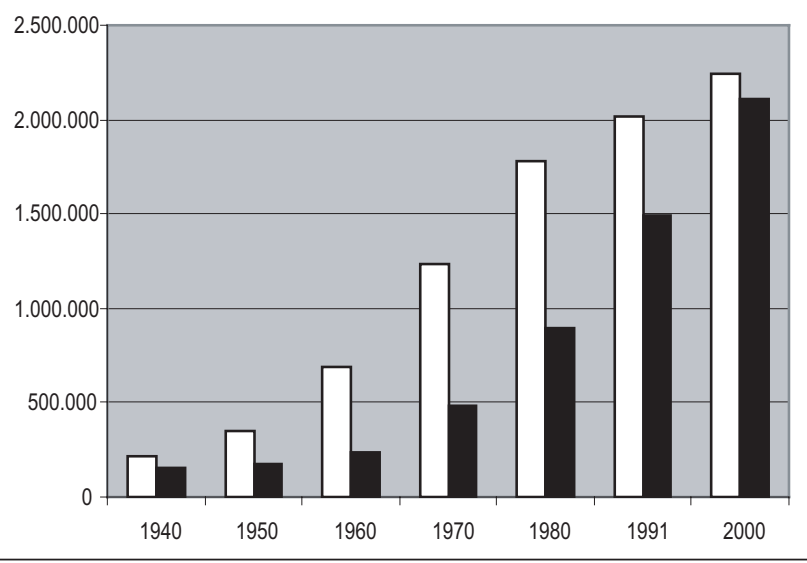

Fonte: IBGE. Censos Demográficos 1940 a 2000.

(1) Municipios metropolitanos menos Belo Horizonte.

A participação relativa da capital mineira no incremento do total da população da RMBH tem diminuído, com grande evidência, desde a década de 40 . Nesse período, Belo Horizonte contribuía com 92,0\% do crescimento da população metropolitana e, em 2000, essa proporção caiu para apenas 26,3\% (Tabela 5). Esse fenômeno de inversão espacial do crescimento demográfico mostra como o comando do crescimento da RMBH não está mais nas mãos da capital mineira.

Esses indicadores expressam o padrão da expansão urbana metropolitana, no qual a inversão espacial do comando do crescimento populacional é uma das suas
GRÁFICO 2

Taxas de Crescimento da População Região Metropolitana de Belo Horizonte - 1940-2000

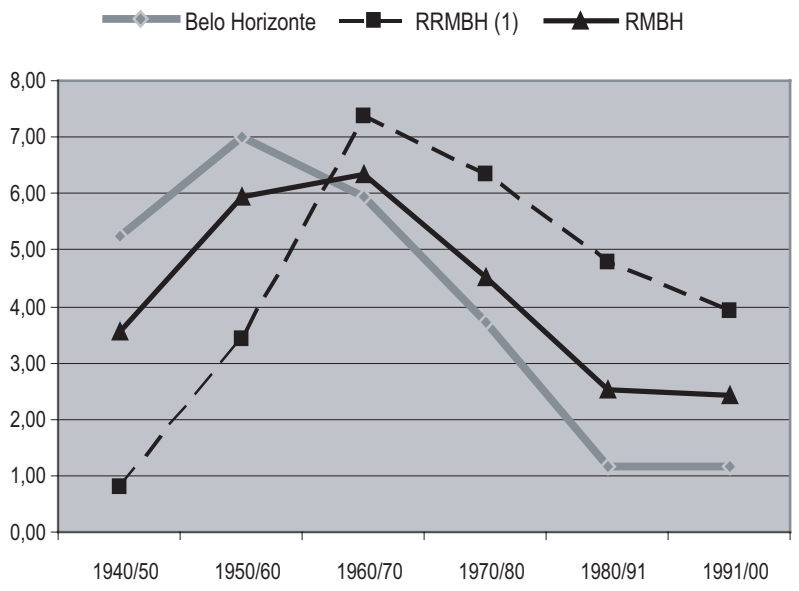

Fonte: IBGE. Censos Demográficos 1940 a 2000.

(1) Municipios metropolitanos menos Belo Horizonte.

dimensões mais importantes. O declínio generalizado das taxas de fecundidade, verificado em todo o país - mais acentuadamente nas grandes cidades -, também teve um papel relevante na redução das taxas de crescimento demográfico das regiões metropolitanas, e de suas capitais em particular. Porém, o papel das migrações foi muito mais importante.

Belo Horizonte nunca foi o destino preferencial dos migrantes de outros Estados: ela atraía, de fato, aqueles que se deslocavam do interior de Minas Gerais. Atualmente, porém, seus emigrantes em direção ao interior também têm aumentado e, conseqüentemente, seu saldo migratório com o interior mineiro tem diminuído (Tabela 6). Como seria de se esperar, os saldos com as outras regiões brasileiras têm sido negativos - à exceção do Nordeste, no caso a Bahia e pouco expressivos. Para o objetivo deste artigo, o mais importante é o grande saldo migratório negativo da capital em relação aos outros municípios metropolitanos. Essa grande emigração da capital, extremamente superior à imigração, tem gerado saldos negativos crescentes, que são os grandes responsáveis pelas baixas taxas de crescimento populacional da capital. Na segunda metade da década passada, o saldo migratório negativo chegou a quase 124 mil pessoas: cerca de $65 \%$ do incremento absoluto da população de Belo Horizonte (Tabela 4). Esse fenômeno, vale a pena sublinhar, tem sido o maior responsável pelo processo de inversão espacial do comando do crescimento demográfico na RMBH e um dos traços marcantes do seu padrão de expansão urbana. 
TABELA 5

Taxas de Crescimento e Participação Relativa no Incremento Populacional

Região Metropolitana de Belo Horizonte - 1940-2000

\begin{tabular}{|c|c|c|c|c|c|c|}
\hline \multirow{3}{*}{ Períodos } & & & & & & m porcenta \\
\hline & \multicolumn{3}{|c|}{ Taxas de Crescimento } & \multicolumn{3}{|c|}{ Participação Relativa } \\
\hline & $\mathrm{BH}$ & RRMBH (1) & $\mathrm{RMBH}$ & $\mathrm{BH}$ & RRMBH (1) & $\mathrm{RMBH}$ \\
\hline $1940 / 50$ & 5,25 & 0,78 & 3,55 & 91,70 & 8,30 & 100,00 \\
\hline $1950 / 60$ & 6,99 & 3,41 & 5,94 & 83,41 & 16,59 & 100,00 \\
\hline $1960 / 70$ & 5,94 & 7,37 & 6,32 & 68,73 & 31,27 & 100,00 \\
\hline $1970 / 80$ & 3,73 & 6,34 & 4,52 & 57,04 & 42,96 & 100,00 \\
\hline 1980/91 & 1,15 & 4,77 & 2,51 & 28,54 & 71,46 & 100,00 \\
\hline $1991 / 2000$ & 1,16 & 3,93 & 2,41 & 26,26 & 73,74 & 100,00 \\
\hline
\end{tabular}

Fonte: IBGE. Censos Demográficos 1940 a 2000.

(1) Municipios metropolitanos menos Belo Horizonte.

TABELA 6

Imigrantes, Emigrantes e Saldos Migratórios, segundo a Origem e o Destino Região Metropolitana de Belo Horizonte - 1986-2000

\begin{tabular}{|c|c|c|c|c|c|c|}
\hline \multirow{2}{*}{$\begin{array}{l}\text { Regiões de Origem } \\
\text { e Destino }\end{array}$} & \multicolumn{3}{|c|}{ 1986-1991 } & \multicolumn{3}{|c|}{$1995-2000$} \\
\hline & Imigrantes & Emigrantes & $\begin{array}{c}\text { Saldo } \\
\text { Migratório }\end{array}$ & Imigrantes & Emigrantes & $\begin{array}{c}\text { Saldo } \\
\text { Migratório }\end{array}$ \\
\hline RMBH & 8.689 & 120.576 & -111.887 & 17.092 & 140.836 & -123.744 \\
\hline Belo Horizonte & 135.577 & 230.060 & -94.483 & 142.069 & 249.660 & -107.591 \\
\hline Norte & 3.352 & 3.718 & -366 & 2.784 & 3.065 & -281 \\
\hline Nordeste & 9.476 & 6.230 & 3.246 & 11.172 & 6.712 & 4.460 \\
\hline Sudeste & 21.487 & 29.966 & -8.479 & 20.766 & 24.057 & -3.291 \\
\hline Sul & 2.372 & 2.891 & -519 & 2.781 & 2.673 & 108 \\
\hline Centro-Oeste & 4.305 & 6.214 & -1.909 & 4.026 & 6.306 & -2.280 \\
\hline Interior de Minas Gerais & 69.102 & 44.106 & 24.996 & 83.448 & 66.011 & 17.437 \\
\hline
\end{tabular}

Fonte: IBGE. Censos Demográficos 1991 a 2000.

Esse padrão de expansão urbana da RMBH tem obedecido às mesmas direções espaciais da expansão da cidade de Belo Horizonte, seguindo, regra geral, seu rígido sistema viário. Historicamente, foram se formando os seis grandes Vetores de Expansão Urbana Metropolitanos (Veum): oeste, norte-central, norte, leste, sul e sudoeste (Mapa 1). ${ }^{1}$

$\mathrm{O}$ vetor oeste começa a se constituir, definitivamente, na década de 40: segue a rota da Avenida Amazonas até o Barreiro e se desdobra em direção, principalmente, às cidades de Contagem e Betim. Em 1941, o Governo do Estado criou, em Contagem, a Cidade Industrial, com o intuito de atrair novas indústrias, entretanto, não teve muito êxito. ${ }^{2}$ A implantação da siderúrgica Mannesmann, no Barreiro, na primeira metade dos anos 50, contribuiu para potencializar a capacidade de atração industrial da região, fortemente limitada pela insuficiência de energia e trans- porte. Posteriormente, no final da década e início dos anos 60, superados os entraves da infra-estrutura, a Cidade Industrial inicia seu processo de consolidação. Em 1967, com a implantação da Refinaria Gabriel Passos, da Petrobras, Betim integra-se ao processo de expansão do vetor oeste da RMBH. Mas somente na década de 70, o município consolida-se como região privilegiada para investimentos industriais, devido à implantação da fábrica de automóveis Fiat em 1976, e de um amplo setor industrial metalmecânico (BRITO; SOUZA, 1996).

Esse importante corredor industrial estimulou tanto a construção de vários conjuntos habitacionais, por iniciativa governamental, quanto a construção de loteamentos para a população de baixa renda, pelo capital imobiliário. Essa intensa ocupação demográfica deu origem ao processo de conurbação de Belo Horizonte com o município de 
MAPA 1

Vetores de Expansão Urbana

Região Metropolitana de Belo Horizonte - 2002

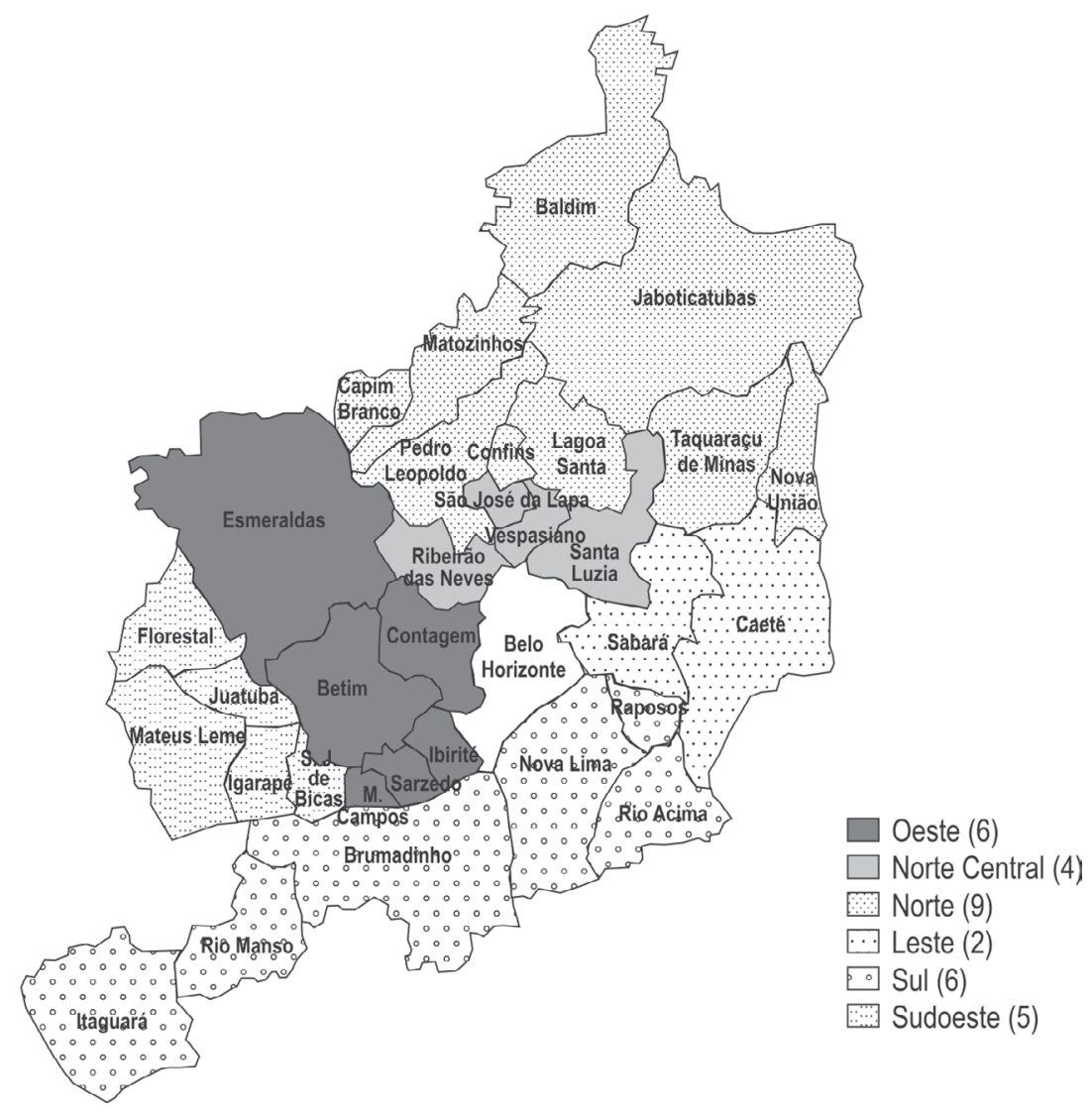

Contagem, e deste com o de Betim. Apesar da realização de investimentos estatais necessários à implantação do parque industrial, a fragilidade do controle público sobre o uso e a ocupação do solo permitiu ampla liberdade de atuação ao capital imobiliário - fato que gerou assentamentos sem a necessária infra-estrutura urbana. A incorporação definitiva de Ibirité ao vetor oeste, com um crescimento populacional acelerado, nas duas últimas décadas, é exemplar dessa expansão imobiliária desordenada. A grande expansão urbana metropolitana por intermédio do vetor oeste tem sua identidade na combinação entre crescimento industrial e urbanização desordenada, fortemente impulsionada pelo crescimento demográfico ativado pelas migrações intrametropolitanas (BRITO; SOUZA, 1996; 1998).

$\mathrm{O}$ vetor norte de expansão teve sua origem em Belo Horizonte, nas regiões da Pampulha e Venda Nova, e de- senvolveu-se a partir dos eixos das Avenidas Antônio Carlos e Cristiano Machado. Para melhor compreensão de sua dinâmica, esse vetor pode ser divido nas regiões norte-central e norte propriamente dita. O norte-central, mais densamente povoado e com maior importância para a dinâmica da RMBH, abrange os municípios de Santa Luzia, Vespasiano e Ribeirão das Neves. E o norte tem como principais municípios: Pedro Leopoldo e Lagoa Santa.

No vetor norte-central, o caso do município de Ribeirão das Neves é clássico. Segundo Costa (2004), havia um considerável número de pequenas propriedades de terra que ocupavam apenas $13 \%$ do município. O restante do território era constituído por grandes propriedades, caracterizadas, principalmente, pela baixa produtividade. As terras do município eram pouco férteis, havendo, em algumas áreas, processos erosivos acentuados. Mesmo com 
terras de tão baixa qualidade, a principal atividade econômica era a produção de hortigranjeiros para atender o mercado da capital mineira.

Considerando a baixa produtividade de sua terra e a proximidade espacial de Ribeirão das Neves e Belo Horizonte - em franca expansão nas décadas de 60 e 70 - os loteamentos para assentamentos populares passaram a representar uma alternativa econômica mais atraente para os grandes proprietários de terras. A possibilidade de industrialização esbarrava na inexistência de uma infra-estrutura adequada para a expansão do capital industrial, além de uma reduzida oferta de mão-de-obra, já que sua população era extremamente escassa até os anos 60 . Foram justamente os loteamentos populares - e não qualquer possibilidade de crescimento de oferta de empregos - os responsáveis pelo notável crescimento demográfico do município na década de 60 até os dias atuais.

Outros municípios, como Santa Luzia e Vespasiano, também situados no vetor norte-central, apresentavam além dos loteamentos populares - condições mais favoráveis para a instalação de plantas industriais, devido a estímulos governamentais por meio da criação de distritos industriais. Entretanto, esses municípios não conseguiram reproduzir o crescimento industrial do vetor oeste. Com a predominância demográfica de Ribeirão das Neves e suas altas taxas de crescimento demográfico, o vetor norte-central acabou se tornando um verdadeiro "pólo de atração de pobreza".

$\mathrm{O}$ vetor norte, no extremo da RMBH, teve seu crescimento vinculado à criação de algumas indústrias de cimento e derivados, desde a década de 60, no município de Pedro Leopoldo. Lagoa Santa, além de ser uma base da Aeronáutica, também se distingue como uma área de condomínios e sítios para a classe média e alta. A construção do aeroporto de Confins, nos anos 80, até o momento, não foi suficiente para viabilizar sua maior expansão. A interação demográfica desse vetor com o núcleo da RMBH é bastante inferior à do vetor norte-central.

Constituído dos municípios de Caeté e Sabará, o vetor leste, assim como boa parte da Região Norte da RMBH, também teve origem na expansão da Avenida Cristiano Machado e do bairro Cidade Nova. Apesar de apresentar uma importância demográfica menor que a dos dois vetores analisados anteriormente, ele também se integra ao espaço urbano metropolitano com loteamentos para a população de baixa renda que praticamente criaram uma cornubação de Sabará com a capital mineira. Note-se que esta cidade colonial tem-se transformado em município-dormitório para muitos que trabalham em Belo Horizonte (BRITO; SOUZA, 1998).

Os municípios de Nova Lima e Brumadinho são os principais do vetor sul, e o primeiro situa-se em área contígua à zona sul de Belo Horizonte. A expansão desse vetor foi potencializada pela construção do BH Shopping, na década de 70, e pela expansão da Avenida Nossa Senhora do Carmo e da BR-040. A instalação desse shopping constitui um marco no processo de ocupação da área, pois acelerou o crescimento da metrópole sobre Nova Lima (COSTA, 2004). Além disso, a criação e o rápido desenvolvimento do bairro Belvedere III provocou uma supervalorização dos terrenos nessa região, que foi determinante para a consolidação desse vetor.

Essa região é caracterizada fundamentalmente pela eficiente atuação combinada do mercado imobiliário e das companhias mineradoras, ambas articuladas, distinguindose dos outros vetores pela ocupação dos loteamentos por uma população de renda mais elevada, em boa parte sob a forma de condomínios. A construção desses condomínios iniciou-se no começo na década de 60 com o Retiro das Pedras, em Brumadinho, e o Serra Del Rey, em Nova Lima, e proliferou-se nos últimos 20 anos. Vale ressaltar que o preço do solo - regulado pelo mercado imobiliário, como salienta Cardoso (2001) - tem um forte componente especulativo, pois aposta na formação de estoques para administrar a valorização do preço da terra urbana. Assim, este preço torna-se uma poderosa ferramenta para selecionar o acesso dos emigrantes às diversas áreas ou municípios metropolitanos. O grande monopólio da propriedade de terra em Nova Lima, por exemplo, possibilita que o mercado imobiliário disponibilize seus estoques segundo suas necessidades de valorização, para diferentes fins. Esse fato contribui para selecionar os emigrantes segundo as exigências da expansão urbana que mais lhes interessa.

$\mathrm{O}$ crescimento do vetor sudoeste tem sido produto não só da sua interação com o núcleo da $\mathrm{RMBH}$ - o município de Belo Horizonte -, mas também com o vetor oeste. A sua expansão é recente e, até os anos 80 , era comandada pelo município de Mateus Leme que, dividido, deu origem ao de Juatuba. A existência de uma indústria de cerveja na região não foi suficiente para garantir o crescimento sustentado da região. Igarapé, outro município do vetor, faz parte do cinturão de produção de hortigranjeiros para a população da $\mathrm{RMBH}$, principalmente a de Belo Horizonte. Na última década, o município que mais cresceu demograficamente, sem nenhuma contrapartida econômica satisfatória, foi o de 
Esmeraldas, onde residiam, em 2000, mais de um terço da população do vetor sudoeste.

Os indicadores demográficos são significativos para mostrarem a dinâmica desses vetores entre 1970 e 2000. Há uma grande concentração populacional, ainda que decrescente, no núcleo da RMBH, a partir do qual os vetores se expandiram: em 2000, nele residia pouco mais da metade da população metropolitana (Tabela 7). Essa concentração torna-se ainda mais notável quando se acrescentam os dois principais vetores de expansão - o oeste e o norte-central e então a população residente chega a quase $90,0 \%$. Acrescentando-se os vetores leste (principalmente Sabará) e sul (em particular Nova Lima), esse espaço urbano, construído em função dos dois principais vetores de ex- pansão cujo ponto de partida foi a própria capital, constitui junto com ela o verdadeiro aglomerado metropolitano.

O crescimento demográfico do vetor norte-central tem sido o mais acelerado desde os anos 70, seguido pelo oeste - ainda que ambos estejam passando por uma expressiva desaceleração. Ao contrário deles, outros vetores - cuja expansão tem sido mais recente - mantiveram seu crescimento, mesmo que numa proporção muito menor. Dentro do processo de redistribuição e inversão espacial do crescimento populacional, o núcleo da RMBH tende a uma certa estagnação demográfica (Tabela 8).

Os dados sobre a velocidade do crescimento populacional devem ser analisados acompanhados da participação relativa no crescimento absoluto da população. São

TABELA 7

População, segundo Vetores de Expansão Urbana

Região Metropolitana de Belo Horizonte - 1970-2000

\begin{tabular}{|c|c|c|c|c|}
\hline Vetores de Expansão & 1970 & 1980 & 1991 & 2000 \\
\hline RMBH & 1.719 .490 & 2.676 .392 & 3.515 .001 & 4.346 .684 \\
\hline Belo Horizonte & 1.235 .030 & 1.780 .855 & 2.020 .161 & 2.238 .526 \\
\hline Oeste & 168.558 & 404.630 & 713.198 & 1.002 .649 \\
\hline Norte-Central & 47.437 & 152.198 & 336.545 & 523.180 \\
\hline Norte & 77.057 & 97.295 & 130.177 & 165.408 \\
\hline Leste & 70.315 & 94.838 & 122.989 & 151.761 \\
\hline Sul & 81.361 & 90.332 & 108.148 & 128.896 \\
\hline Sudoeste & 39.732 & 56.244 & 83.783 & 136.264 \\
\hline
\end{tabular}

Fonte: IBGE. Censos Demográficos 1970 a 2000.

TABELA 8

Taxas Anuais de Crescimento e Participação Relativa no Incremento Populacional, segundo Vetores de Expansão Urbana Região Metropolitana de Belo Horizonte - 1970-2000

\begin{tabular}{|c|c|c|c|c|c|c|}
\hline \multirow{3}{*}{ Vetores de Expansão } & & & & & & Em porcenta \\
\hline & \multicolumn{3}{|c|}{ Taxas de Crescimento } & \multicolumn{3}{|c|}{ Participação Relativa } \\
\hline & $1970 / 80$ & $1980 / 91$ & $1991 / 2000$ & $1970 / 80$ & $1980 / 91$ & $1991 / 2000$ \\
\hline RMBH & 4,52 & 2,51 & 2,43 & 100,00 & 100,00 & 100,00 \\
\hline Belo Horizonte & 3,73 & 1,15 & 1,17 & 57,04 & 28,54 & 26,26 \\
\hline Oeste & 9,15 & 5,29 & 3,93 & 24,67 & 36,80 & 34,80 \\
\hline Norte-Central & 12,36 & 7,48 & 5,12 & 10,95 & 21,98 & 22,44 \\
\hline Norte & 2,36 & 2,68 & 2,75 & 2,11 & 3,92 & 4,24 \\
\hline Leste & 3,04 & 2,39 & 2,41 & 2,56 & 3,36 & 3,46 \\
\hline Sul & 1,05 & 1,65 & 2,01 & 0,94 & 2,12 & 2,49 \\
\hline Sudoeste & 3,54 & 3,69 & 5,66 & 1,73 & 3,28 & 6,31 \\
\hline
\end{tabular}

Fonte: IBGE. Censos Demográficos 1970 a 2000. 
justamente a capital e os vetores, que tem desacelerado o seu crescimento, os grandes responsáveis pelo incremento populacional da RMBH, ou seja, pela ordem, vetor oeste, Belo Horizonte e vetor norte. Como já foi dito, o notável é que, recentemente, o comando do crescimento populacional da RMBH - diferentemente da década de 70 - tem sido responsabilidade dos dois vetores mencionados: quase $60,0 \%$. Considerando-se os outros vetores, essa proporção chega perto dos 74,0\%. Trata-se, sem dúvida, de uma redistribuição espacial da população muito marcante - e este é um dos traços do processo da expansão urbana recente da RMBH (Tabela 8).

\section{MIGRAÇÕES INTRAMETROPOLITANASE MOBILIDADE PENDULAR NA RMBH}

A migração intrametropolitana, ou seja, a mobilidade da população entre os seus diferentes municípios, é um bom indicador do grau de interação entre eles e, portanto, da densidade social do espaço metropolitano construído por meio dos vetores de expansão. No caso da RMBH - assim como nos principais aglomerados metropolitanos no Brasil - essas migrações têm sido resultantes, principalmente, do movimento do capital imobiliário junto com o Estado, com o objetivo de redistribuir social e espacialmente a população.

A análise da migração intrametropolitana levará em consideração a direção de seu fluxo mais importante, ou seja, o dos emigrantes de Belo Horizonte para os diferentes vetores de expansão urbana, não só pela sua dimensão, mas também pela importância para testar a hipótese da redistribuição espacial da pobreza. Chama a atenção, de imediato, a grande concentração dos emigrantes nos dois qüinqüênios. Já havia sido mostrado que essa grande evasão populacional da capital, junto com o declínio das taxas de fecundidade total, têm sido os grandes responsáveis pela redução das taxas de crescimento demográfico (Tabela 9).

Os municípios pertencentes aos vetores oeste e nortecentral têm sido os que mais recebem os emigrantes: na segunda metade dos anos 80, representavam cerca de $87,0 \%$ do total do fluxo. Há uma grande consistência nesses resultados; afinal de contas, são os vetores que mais crescem demograficamente, ainda que tenham características econômicas muito distintas. Comparado com o anterior, o período mais recente analisado mostra um acréscimo no número de emigrantes para todos os vetores - ainda que, no caso do oeste, esse número tenha se mantido praticamente estável. Houve uma redução relativa dos dois grandes vetores de expansão, e esse fenômeno foi favorável aos outros: o sul e o sudoeste mais do que dobraram o número dos seus imigrantes originários de Belo Horizonte.

As emigrações de Belo Horizonte têm alimentado a expansão urbana na RMBH e são fundamentais na constituição do espaço social metropolitano que se articula por meio dos vetores de expansão. É no espaço metropolitano que essa migração reproduz as desigualdades sociais inerentes às características dos seus diferentes vetores, dando sentido à expansão urbana metropolitana. De fato, uma evidência mais precisa sobre a reprodução das desigualdades reivindica uma análise dos atributos dos emigrantes. Como não houve mudanças substanciais entre os dois períodos (1986/1991 e 1995/2000), a reflexão se desenvol-

TABELA 9

Emigrantes, segundo Vetores de Expansão Urbana Região Metropolitana de Belo Horizonte - 1986-2000

\begin{tabular}{|c|c|c|c|c|}
\hline \multirow{2}{*}{ Vetores de Expansão } & \multicolumn{2}{|c|}{ 1986-91 } & \multicolumn{2}{|c|}{ 1995-2000 } \\
\hline & Nos Absolutos & $\%$ & $\mathrm{~N}^{\circ s}$ Absolutos & $\%$ \\
\hline Belo Horizonte & 120.574 & 100,00 & 140.836 & 100,00 \\
\hline Oeste & 58.126 & 48,21 & 58.541 & 41,57 \\
\hline Norte-Central & 46.076 & 38,21 & 51.844 & 36,81 \\
\hline Norte & 3.664 & 3,04 & 7.005 & 4,97 \\
\hline Leste & 5.425 & 4,50 & 7.686 & 5,46 \\
\hline Sul & 2.470 & 2,05 & 5.354 & 3,80 \\
\hline Sudoeste & 4.813 & 3,99 & 10.406 & 7,39 \\
\hline
\end{tabular}

Fonte: IBGE. Censos Demográficos 1991 e 2000. 
verá, exclusivamente, sobre os emigrantes mais recentes (BRITO; SOUZA, 1998).

A estrutura etária é aquela prevista pela teoria das migrações, pois ela é seletiva por idade: encontra-se uma grande concentração de emigrantes entre 15 e 39 anos (55,0\%, aproximadamente), e, nessa faixa, observa-se predominância de mulheres (Gráfico 3). Deve ser mencionado que os dados de migração de data fixa não incluem, logicamente, os nascidos no período mencionado. Como

\section{GRÁFICO 3}

Estrutura Etária dos Emigrantes para os Outros Municípios Metropolitanos, por Sexo Belo Horizonte - 2000
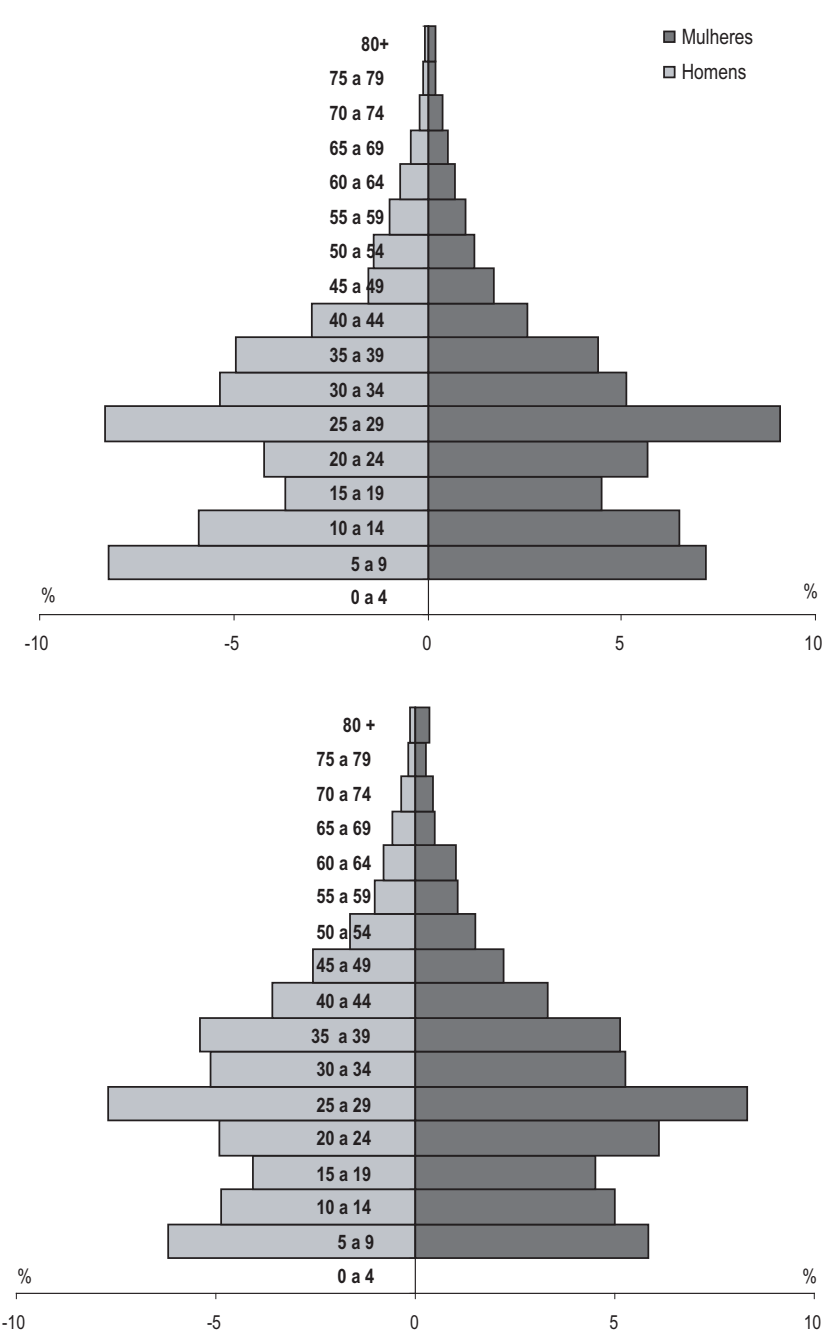

Fonte: IBGE. Censo Demográfico 2000 se sabe, o Censo Demográfico 2000 pergunta aos residentes: "Em qual município residia em 1995?".

Segundo as respostas dadas sobre a renda de sua ocupação principal, a maioria dos emigrantes intrametropolitanos vindos de Belo Horizonte é pobre. Considerando inicialmente o salário mediano dos emigrantes, constata-se que a metade deles recebe menos do que 2,2 salários mínimos. O salário médio é quase o dobro - fato resultante da grande disparidade entre os salários dos emigrantes para os diferentes vetores de expansão. A variação entre os salários medianos, segundo os diferentes destinos, não é muito grande: fica em torno de 2 a 2,5 salários mínimos. A grande diferença é o vetor sul, onde a metade dos emigrantes recebe, pelo menos, 7,3 salários mínimos. É a região que concentra condomínios para a população de nível de renda mais alta - o que justifica essa discrepância (Tabela 10).

A tese de que a emigração intrametropolitana promove uma substancial redistribuição da população mais pobre de Belo Horizonte em direção aos principais vetores de expansão urbana metropolitana parece confirmada pelos dados. Os salários médios e medianos dos emigrantes para os vetores oeste e o norte-central (que são os que recebem o maior número deles, quase $80,0 \%$ ) estão entre os mais baixos e com as menores diferenças entre eles. Este fato sugere uma distribuição mais homogênea dos salários ou, em outras palavras, uma grande homogeneização da pobreza. Por outro lado, a maior diferença entre os salários médios e medianos ocorre justamente no vetor sul, onde eles têm os maiores valores - o que sugere maior dispersão na distribuição dos salários, certamente acompanhada de maior concentração.

Com certeza, a distribuição dos salários poderá colocar mais luz nas reflexões. Consistentemente com os indica-

TABELA 10

Salário Médio e Mediano dos Emigrantes Maiores de 10 Anos, segundo Vetores de Expansão Urbana Belo Horizonte - 2000

\begin{tabular}{lcc} 
& & Em salários mínimos \\
\hline Vetor de Expansão & Média & Mediana \\
\hline Belo Horizonte & $\mathbf{4 , 1}$ & $\mathbf{2 , 2}$ \\
Oeste & 3,7 & 2,5 \\
Norte-Central & 2,8 & 2,0 \\
Norte & 5,1 & 2,5 \\
Leste & 3,3 & 2,0 \\
Sul & 13,9 & 7,3 \\
Sudoeste & 6,0 & 1,9 \\
\hline
\end{tabular}

Fonte: IBGE. Censo Demográfico 2000. 
dores sintéticos, ela mostra quase a metade dos emigrantes com salários inferiores a dois mínimos, e apenas 5,5\% com mais de dez - o que confirma a predominância dos mais pobres. Mas as diferenças entre as distribuições dos salários dos emigrantes para os vários vetores são mais esclarecedoras. Mais de 56\% dos que se mudaram para o norte-central, um dos que mais recebe emigrantes, têm uma remuneração da ocupação principal inferior a dois salários mínimos, e há apenas 2,1\% com mais dez. Em situação semelhante, encontram-se os emigrantes para os vetores leste e sudoeste. Nesse último, a proporção dos mais pobres chega a mais de $62 \%$. Os emigrantes que se mudaram para o vetor oeste, o destino preferencial deles, apresentavam uma distribuição de salários mais próxima da média (Tabela 11).

A grande especificidade é a dos emigrantes para o vetor sul: os mais pobres são pouco mais de $21 \%$, enquanto aqueles com mais de 10 salários mínimos de remuneração chegam a quase $42 \%$. Tal distribuição, muito distinta da média, acontece nas regiões com os terrenos mais valorizados, como os condomínios, em que uma população mais pobre é necessária para a prestação de serviço e para o comércio, indispensáveis à reprodução das famílias de renda mais alta (BRITO; SOUZA, 1998).

Sabe-se que o número de mulheres emigrantes é maior do que o dos homens. Desse modo, uma informação adicional para a análise seria a distribuição do salário da ocupação principal segundo o sexo (Gráfico 4). A porcentagem de mulheres com uma remuneração igual a ou menor do que dois salários mínimos é muito superior à dos homens. Nas remunerações mais altas, a proporção relativa dos homens é sempre superior. Não se trata de algo surpreendente: apenas reflete o padrão de organização da sociedade e da economia, no qual há discriminação por sexo desfavorável às mulheres - até mesmo na escala de remuneração do trabalho. Mais ainda: o mercado de trabalho reserva para as mulheres grande parte das atividades do setor serviços - em particular, dos serviços domésticos - com uma remuneração extremamente baixa.

O nível educacional é outro atributo dos emigrantes que poderá ampliar a análise sobre as migrações e o processo de segregação social e espacial no aglomerado metropolitano de Belo Horizonte. Somente a população adulta, com

\section{GRÁFICO 4}

Distribuição dos Emigrantes para os Outros Municípios Metropolitanos, por Sexo, segundo Renda da Ocupação Principal (1) Belo Horizonte - 2000

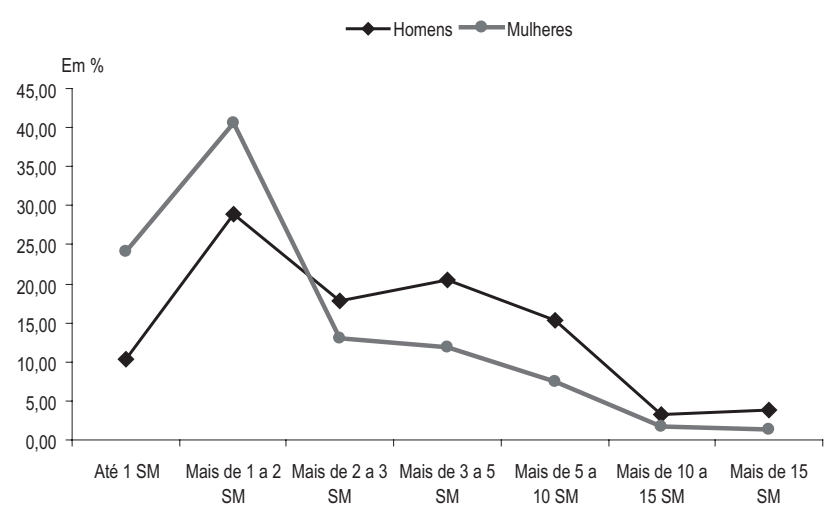

Fonte: IBGE Censo Demográfico 2000.

(1) Em salários mínimos(SM).

TABELA 11

Distribuição dos Emigrantes Maiores de 10 Anos, por Renda da Ocupação Principal (1), segundo Vetores de Expansão Urbana Belo Horizonte - 2000

\begin{tabular}{|c|c|c|c|c|c|c|c|c|}
\hline \multirow[b]{2}{*}{ Vetores de Expansão } & \multicolumn{7}{|c|}{ Renda da Ocupação Principal em SM (\%) } & \multirow{2}{*}{$\begin{array}{l}\text { Total de } \\
\text { Emigrantes } \\
\left(\mathrm{N}^{\text {os }} \text { Abs.) }\right.\end{array}$} \\
\hline & Até $1 \mathrm{SM}$ & $\begin{array}{c}\text { Mais de } 1 \\
\text { a } 2 \mathrm{SM}\end{array}$ & $\begin{array}{c}\text { Mais de } 2 \\
\text { a } 3 \mathrm{SM}\end{array}$ & $\begin{array}{c}\text { Mais de } 3 \\
\text { a } 5 \mathrm{SM}\end{array}$ & $\begin{array}{c}\text { Mais de } 5 \\
\text { a } 10 \mathrm{SM}\end{array}$ & $\begin{array}{c}\text { Mais de } 10 \\
\text { a } 15 \mathrm{SM}\end{array}$ & $\begin{array}{c}\text { Mais de } \\
15 \mathrm{SM}\end{array}$ & \\
\hline Belo Horizonte & 15,68 & 33,42 & 15,94 & 17,15 & 12,28 & 2,63 & 2,90 & 64.042 \\
\hline Oeste & 12,80 & 31,34 & 16,39 & 19,70 & 14,99 & 2,94 & 1,85 & 28.432 \\
\hline Norte-Central & 17,53 & 38,71 & 17,16 & 16,09 & 8,37 & 1,13 & 1,01 & 22.877 \\
\hline Norte & 21,40 & 25,15 & 10,94 & 15,76 & 16,31 & 4,85 & 5,61 & 2.907 \\
\hline Leste & 18,16 & 34,59 & 14,93 & 15,34 & 13,52 & 2,31 & 1,15 & 3.469 \\
\hline Sul & 6,51 & 14,50 & 9,58 & 9,39 & 18,23 & 12,61 & 29,18 & 2.704 \\
\hline Sudoeste & 26,42 & 36,03 & 14,43 & 12,51 & 6,82 & 0,85 & 2,96 & 3.653 \\
\hline
\end{tabular}

Fonte: IBGE. Censos Demográficos 1940 a 2000

(1) Em salários mínimos (SM). 
20 anos ou mais, será objeto das reflexões: ao estudá-la, será utilizada a informação sobre os anos de estudo. Os analfabetos e aqueles com menos de quatro anos de estudo serão considerados "analfabetos funcionais" - o que parece razoável, levando em conta a idade da população escolhida, a qualidade insuficiente do sistema de ensino e as exigências educacionais atuais do mercado de trabalho. Como seria de se esperar, em função da análise dos anos de estudo, a proporção de analfabetos funcionais é alta: $36,2 \%$. Em alguns vetores, como o norte-central, a porcentagem chega a cerca de $42 \%$; e no sudoeste ultrapassa a metade dos emigrantes. O vetor sul - de acordo com os dados sobre os salários e com suas próprias características analisadas anteriormente - é o que apresenta a menor proporção de analfabetos funcionais (Tabela 12 e Gráfico 5).

As desigualdades encontradas entre as características dos emigrantes mostram a relação entre a redistribuição espacial da população e o processo de segregação social existente segundo os diferentes vetores de expansão urbana metropolitana. Em grande medida, o padrão de segregação é comandado pelo capital imobiliário, com a colaboração dos investimentos públicos estatais quanto à definição do diferencial de preços do solo urbano. Entretanto, esse padrão promove uma redistribuição social da população, mas não homogênea. Isso é fundamental na constituição do espaço urbano metropolitano. Os fluxos migratórios para os vetores onde a população é mais pobre tendem a ser mais homogêneos: o norte-central e o oeste - que é o destino de cerca de 80,0\% dos emigrantes - são exemplares. Há rigidez nas fronteiras espaciais e sociais, uma delimitação territorial notável. Por outro lado, os emi- grantes para o vetor sul, mesmo tendo a maior proporção de pessoas com alto nível de renda e educação, constituem um fluxo mais heterogêneo.

Mesmo que em função da profunda crise urbana existam favelas ou condomínios, onde o território é fortemente delimitado, retratando, de um lado e de outro, um espaço social impenetrável, a estrutura social e espacial urbana requer uma maior flexibilidade social na distribuição da população em função das necessidades do mercado de trabalho. A mão-de-obra exigida pela população mais rica para oferecer as mercadorias e os serviços indispensáveis à sua reprodução, no caso brasileiro, ainda estão distante de dispensar

\section{GRÁFICO 5}

Distribuição dos Emigrantes para os Outros

Municípios Metropolitanos, por Sexo, segundo Anos de Estudo Belo Horizonte -2000

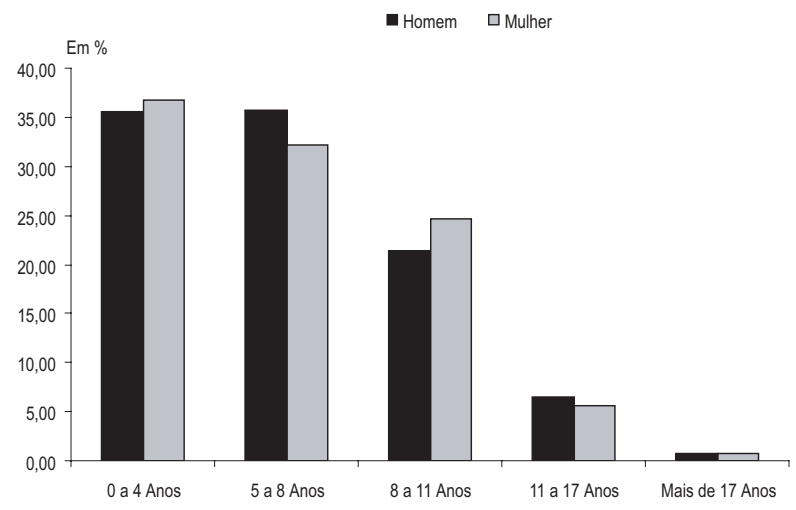

Fonte: IBGE. Censo Demográfico 2000

TABELA 12

Distribuição dos Emigrantes com 20 Anos ou Mais, por Anos de Estudo, segundo Vetores de Expansão Urbana Belo Horizonte - 2000

\begin{tabular}{|c|c|c|c|c|c|c|}
\hline \multirow{3}{*}{ Vetores de Expansão } & \multicolumn{5}{|c|}{ Anos de Estudo (\%) } & \multirow{3}{*}{$\begin{array}{l}\text { Total dos } \\
\text { Emigantes } \\
\left(\mathrm{N}^{\text {os }} \text { Abs.) }\right.\end{array}$} \\
\hline & 0 a 4 & 5 a 8 & 8 a 11 & 11 a 17 & Mais de & \\
\hline & Anos & Anos & Anos & Anos & 17 Anos & \\
\hline Belo Horizonte & 36,18 & 33,97 & 23,13 & 6,03 & 0,69 & 97.833 \\
\hline Oeste & 30,86 & 35,36 & 27,14 & 5,96 & 0,68 & 42.027 \\
\hline Norte-Central & 41,68 & 36,29 & 19,84 & 1,65 & 0,55 & 35.160 \\
\hline Norte & 35,34 & 24,13 & 29,06 & 11,01 & 0,46 & 4.779 \\
\hline Leste & 34,02 & 36,06 & 22,50 & 6,09 & 1,32 & 5.382 \\
\hline Sul & 19,31 & 12,85 & 20,90 & 45,65 & 1,29 & 3.790 \\
\hline Sudoeste & 52,59 & 30,43 & 12,67 & 3,47 & 0,85 & 6.695 \\
\hline
\end{tabular}

Fonte: IBGE. Censo Demográfico 2000 
a proximidade de uma parcela da população mais pobre.

Para melhor elucidar a relação entre a residência e o local de trabalho dentro do padrão de urbanização, torna-se necessário analisar a mobilidade pendular - ou seja, aquela realizada por quem reside em um determinado município e realiza suas atividades em outro, com regularidade.

Neste artigo, os pendulares são aqueles que residem em outro município da RMBH e trabalham em Belo Horizonte, ou, ao contrário, moram em Belo Horizonte e trabalham em outro município metropolitano. A mobilidade pendular é uma função, principalmente, da migração intrametropolitana determinada pela expansão dos vetores urbanos e metropolitanos. Ela - mais do que as migrações - é uma evidência do vigor do tecido social construído sobre o espaço metropolitano, onde o modo de expansão urbana cria uma distância necessária entre o lugar de residência e o de trabalho. Isso pode se dar porque a população mais rica escolheu residir em lugares onde as externalidades positivas compensam os custos adicionais da distância, ou, no caso dos mais pobres, pela coerção do mercado imobiliário e, em menor proporção, em função do mercado de trabalho.

Segundo a pesquisa "Origem e Destino", 212.397 pessoas residem em outros municípios metropolitanos e trabalham em Belo Horizonte, sendo que a maioria procede dos vetores oeste e norte-central - o que faz sentido como decorrência do tamanho da população dos vetores e do volume da emigração de Belo Horizonte. O movimento em sentido contrário é bem menor e concentrado no vetor oeste, em função das possibilidades de seu mercado de trabalho (Tabela 13).

A desigualdade na construção do tecido social do espaço metropolitano pode ser mais uma vez compreendida quando se observa que quase $70,0 \%$ dos que fazem o movimento pendular para trabalharem em Belo Horizonte residiam antes nessa mesma cidade, sendo que em alguns municípios essa proporção ultrapassa essa média, como é o caso

TABELA 13

Movimentos Pendulares por Motivo de Trabalho, segundo Vetores de Residência Região Metropolitana de Belo Horizonte - 2002

\begin{tabular}{lcc}
\hline $\begin{array}{l}\text { Vetores de } \\
\text { Residência }\end{array}$ & $\begin{array}{c}\text { Residem na RRMBH (1) } \\
\text { e Trabalham em } \\
\text { Belo Horizonte }\end{array}$ & $\begin{array}{c}\text { Residem em } \\
\text { Belo Horizonte } \\
\text { e Trabalham } \\
\text { na RRMBH (1) }\end{array}$ \\
\hline RMBH & 212.397 & 76.404 \\
Oeste & 100.000 & 56.221 \\
Norte-Central & 79.975 & 9.059 \\
Norte & 3.450 & 2.221 \\
Leste & 19.904 & 1.984 \\
Sul & 7.949 & 6.086 \\
Sudoeste & 1.119 & 833 \\
\hline
\end{tabular}

Fonte: FJP. Pesquisa Origem e Destino, 2002.

(1) Municípios metropolitanos menos Belo Horizonte.

TABELA 14

Movimentos Pendulares por Motivo de Trabalho, de Alguns Municípios da RMBH para Belo Horizonte, de Pessoas que Residiam Anteriormente em Belo Horizonte Região Metropolitana de Belo Horizonte - 2002

\begin{tabular}{|c|c|c|c|}
\hline $\begin{array}{l}\text { Municípios da } \\
\text { RMBH }\end{array}$ & $\begin{array}{c}\text { Residem na RMBH e Trabalham } \\
\text { em Belo Horizonte (origem } \mathrm{BH} \text { ) }\end{array}$ & $\begin{array}{c}\text { Residem na RMBH e Trabalham } \\
\text { na RRMBH (1) }\end{array}$ & $\begin{array}{c}\text { Participação } \\
(\%)\end{array}$ \\
\hline RMBH & 143.768 & 212.397 & 67,69 \\
\hline Contagem & 38.699 & 59.177 & 65,40 \\
\hline Ribeirão das Neves & 28.314 & 40.332 & 70,20 \\
\hline Santa Luzia & 20.350 & 29.391 & 69,24 \\
\hline Sabará & 15.056 & 18.762 & 80,25 \\
\hline Ibirité & 13.876 & 20.027 & 69,29 \\
\hline Betim & 9.080 & 16.725 & 54,29 \\
\hline Vespasiano & 7.266 & 9.818 & 74,01 \\
\hline Nova Lima & 3.556 & 5.706 & 62,45 \\
\hline Esmeraldas & 1.259 & 1.904 & 66,12 \\
\hline Outros Municípios & 6.312 & 10.555 & 59,80 \\
\hline
\end{tabular}

Fonte: FJP. Pesquisa Origem e Destino, 2002

(1) Municípios metropolitanos menos Belo Horizonte. 
de Sabará (Tabela 14). Ou seja, provocada em grande parte pelo movimento do capital imobiliário, a migração intrametropolitana leva à mudança de residência, entretanto, devido à forte seletividade da migração, obriga os cidadãos a retornarem diariamente a Belo Horizonte para trabalhar.

Concluindo, os fenômenos observados dentro da expansão dos vetores urbanos metropolitanos da RMBH certamente têm muito em comum com o padrão de outros aglomerados metropolitanos, pelo menos no fundamental - a metropolização da pobreza. No contexto da grande desigualdade social, assim como dos graves desequilíbrios regionais - marcas históricas da sociedade brasileira - as grandes mudanças estruturais ocorridas na segunda metade do século 20 tornaram simultâneas a urbanização e a metropolização. Como conseqüência, o padrão de expansão urbana dos aglomerados metropolitanos, com um crescimento demográfico extremamente acelerado, transferiu o comando desse crescimento para os municípios periféricos à capital, por meio de intensa migração intrametropolitana. Na verdade, essa transferência do comando do crescimento populacional foi resultante da redistribuição espacial da população mais pobre, sob o comando do capital imobiliário e supervisão do poder público. Em síntese, resultante da estrutura social e espacial desses grandes aglomerados metropolitanos, que é alinhavada por uma grande desigualdade social.

\section{NOTAS}

1. Os municípios que formam os vetores são os seguintes: vetor oeste: Betim, Contagem, Ibirité, Mario Campos e Sarzedo; vetor norte-central: Ribeirão das Neves, Santa Luzia,Vespasiano e São José da Lapa; vetor norte: Baldim, Capim Branco, Lagoa Santa, Confins, Jaboticatubas, Matosinho, Nova União, Pedro Leopoldo; vetor leste: Caeté e Sabará; vetor sul: Nova Lima, Brumadinho, Raposos, Rio Acima, Rio Manso; vetor sudoeste: Florestal, Igarapé, São Joaquim de Bicas, Mateus Leme, Juatuba, Esmeraldas.

2. Essa análise da formação dos Vetores de Expansão Urbana Metropolitanos encontra-se em Brito e Souza (2005).

\section{REFERÊNCIAS BIBLIOGRÁFICAS}

BRITO, F.; HORTA, C. A urbanização recente no Brasil e as aglomerações metropolitanas. Cedeplar - IUSSP, 2002.

BRITO, F.; SOUZA, J. A metropolização da pobreza. In: ENCONTRO NACIONAL DE ESTUDOS POPULACIONAIS, 11., 1998, Caxambu. Anais... Belo Horizonte: Abep, 1998.

Mobilidade espacial e expansão urbana: o caso da Região Metropolitana de Belo Horizonte, . In: ENCONTRO NACIONAL DE ESTUDOS POPULACIONAIS, 1996, Caxambu. Anais... Belo Horizonte: Abep, 1996.

BRITO, F.; SOUZA, R. Migração e mobilidade na expansão da região metropolitana de Belo Horizonte: o caso de Nova Lima. Belo Horizonte: Ed. da UFMG, 2005.

CARDOSO, A.L. Desigualdades urbanas e politicas habitacionais. Rio de Janeiro: Observatório de Políticas Urbanas e Gestão Municipal, IPPUR/UFRJ - FASE, 2001. Disponível em: <http://www.ippur.ufrj.br/observatorio/download/ adauto_desig_urb_polhab.pdf $>$.

CARVALHO, J.A.M.; GARCIA, R.A. Estimativas decenais e qüinqüenais de saldos migratórios e taxas líquidas de migração do Brasil, por situação de domicílio, sexo e idade, segundo unidade da federação e macrorregião, entre 1960 e 1990 e estimativas de emigrantes internacionais do periodo 1985/ 1990. Belo Horizonte: Cedeplar/UFMG, 2003. Disponível em: $<$ http://www.cedeplar.ufmg.br/pesquisas/migracao/index.html $>$.

COSTA, H.S.M. Natureza e mercado imobiliário na redistribuição da população metropolitana: notas a partir do Eixo-Sul de Belo Horizonte. In: ENCONTRO NACIONAL DE ESTUDOS POPULACIONAIS, 14., Anais... Caxambu, Abep, 2004.

IPEA/IBGE/NESUR. Caracterização e tendências da rede urbana no Brasil. Campinas: IE/Unicamp, 1999.

Fausto Brito: Doutor em Demografia, Professor e Pesquisador do Cedeplar e do Departamento de Demografia da UFMG.

Joseane de Souza: Mestre em Demografia pelo Cedeplar da UFMG.

Artigo recebido em 3 de junho de 2005.

Aprovado em 1 de julho de 2005. 